\title{
Supplementary files
}

\section{September Arctic Sea Ice minimum prediction - a new skillful statistical approach}

M. Ionita ${ }^{1 *}$, K. Grosfeld ${ }^{1}$, P. Scholz ${ }^{1}$, R. Treffeisen ${ }^{1}$ and G. Lohmann ${ }^{1,2}$

(1) Alfred Wegener Institute Helmholtz Center for Polar and Marine Research, Bremerhaven, Germany

(2) MARUM - Center for Marine Environmental Sciences, University of Bremen, Bremen, Germany

*Corresponding author:

Email: Monica.Ionita@awi.de

Address:

Alfred Wegener Institute Helmholtz Centre for Polar and Marine Research

Bussestrasse 24

D-27570 Bremerhaven

Telephone: $+49(471) 4831-1845$

Fax: $+49(471) 4831-1271$ 


\section{Skill measures}

To better assess the skill of the forecast, different statistical metrics have been employed: mean absolute error (MAE), mean square error (MSE), root mean square error (RMSE), normalized root mean square error (NMRSE), Nush - Sutcliffe Efficency (NSE), modified NSE (mNSE), relative NSE (rNSE), index of agreement (d), coefficient of persistence (CP) and coefficient of determination $\left(\mathrm{R}^{2}\right)$.

1. Mean absolute error (MAE)

$$
\text { mae }=\frac{1}{N} \sum_{i=1}^{N}\left|\left(S_{i}-O_{i}\right)\right|
$$

2. Mean square error (MSE)

$$
m s e=\frac{1}{N} \sum_{i=1}^{N}\left(S_{i}-O_{i}\right)^{2}
$$

3. Root mean square error (RMSE)

$$
\text { rmse }=\sqrt{\frac{1}{N} \sum_{i=1}^{N}\left(S_{i}-O_{i)}^{2}\right.}
$$

4. Normalized root mean square error (NRMSE)

$$
\begin{aligned}
& \text { nrmse }=100 \frac{\sqrt{\frac{1}{N} \sum_{i=1}^{N}\left(S_{i}-O_{i}\right)^{2}}}{\text { nval }} \\
& \text { nval }=\left\{\begin{array}{lr}
s d\left(O_{i}\right), & \text { norm }=" s d " \\
O_{\max }-O_{\text {min }}, & \text { norm }=" \text { maxim" }
\end{array}\right.
\end{aligned}
$$

5. Nush - Sutcliffe Efficiency (NSE)

$$
N S E=1-\frac{\sum_{i=1}^{N}\left(S_{i}-O_{i}\right)^{2}}{\sum_{i=1}^{N}\left(O_{i}-\bar{O}\right)^{2}}
$$

NSE (Nush and Sutcliffe, 1970) ranges from -Inf to 1. Essentially, the closer to 1 , the more accurate the model is. NSE $=1$ indicates a prefect forecast model, NSE $=0$ indicates that the model predictions are as accurate as the mean of the observed data and -Inf $<$ NSE $<0$, indicates that the observed mean is better predictor than the model.

6. Modified NSE (mNSE)

$$
m N S E=1-\frac{\sum_{i=1}^{N}\left|S_{i}-O_{i}\right|^{j}}{\sum_{i=1}^{N}\left|O_{i}-\bar{O}\right|^{j}}
$$

7. Relative NSE (rNSE)

$$
r N S E=1-\frac{\sum_{i=1}^{N}\left(\frac{S_{i}-O_{i}}{\bar{O}}\right)^{2}}{\sum_{i=1}^{N}\left(\frac{O_{i}-\bar{O}}{\bar{O}}\right)^{2}}
$$

8. Index of Agreement $(0<=d<=1)$

$$
d=1-\frac{\sum_{i=1}^{N}\left(O_{i}-S_{i}\right)^{2}}{\sum_{i=1}^{N}\left(\left|S_{i}-\bar{O}\right|+\left|O_{i}-\bar{O}\right|\right)^{2}}
$$


The Index of Agreement (d) developed by Willmot (1982) as a standardized measure of the degree of model prediction errors and varies between 0 and 1 . A value of 1 indicates a perfect match and 0 indicates no agreement at all.

9. Coefficient of persistence $(0<=\mathrm{CP}<=1)$.

$$
C P=1-\frac{\sum_{i=2}^{N}\left(S_{i}-O_{i}\right)^{2}}{\sum_{i=1}^{N-1}\left(O_{i+1}-O_{i}\right)^{2}}
$$

The coefficient of persistence compares the predictions of the model with the predictions obtained by assuming that the process is a Wiener process (variance increasing linearly with time), in which case, the best estimate for the future is given by the latest measurement (Kitanidis and Bras, 1980). Persistence model efficiency is a normalized model evaluation statistic that quantifies the relative magnitude of the residual variance (noise) to the variance of the errors obtained by the use of a single persistence model (Moriasi et al., 2007). The coefficient of persistence ranges from 0 to 1 , with $\mathrm{CP}=1$ being the optimal value and it should be larger than 0 to indicate a minimally acceptable performance model. 


\section{References}

Kitanidis, P.K., and Bras, R.L. 1980. Real-time forecasting with a conceptual hydrologic model. 2. Applications and results. Water Resources Research, Vol. 16, No. 6, pp. 1034:1044.

Moriasi, D. N. et al. (2007). Model Evaluation Guidelines for Systematic Quantification of Accuracy in Watershed Simulations. Transactions of the ASABE, 50:(3), 885-900.

Nash, J. E. and Sutcliffe, J. V. 1970: River flow forecasting through conceptual models, Part I - A discussion of principles, J. Hydrol., 10,282-290.

Willmot, C. J. 1981: On the validation of models, Physical Geography, 2,184-194. 
a)

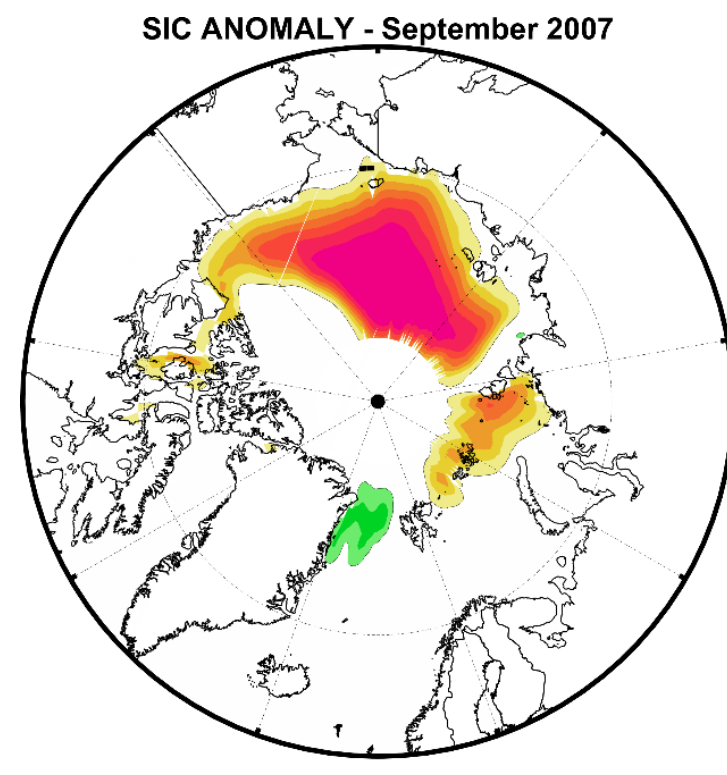

b)

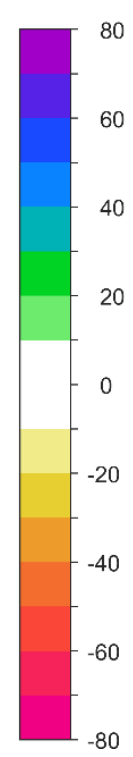

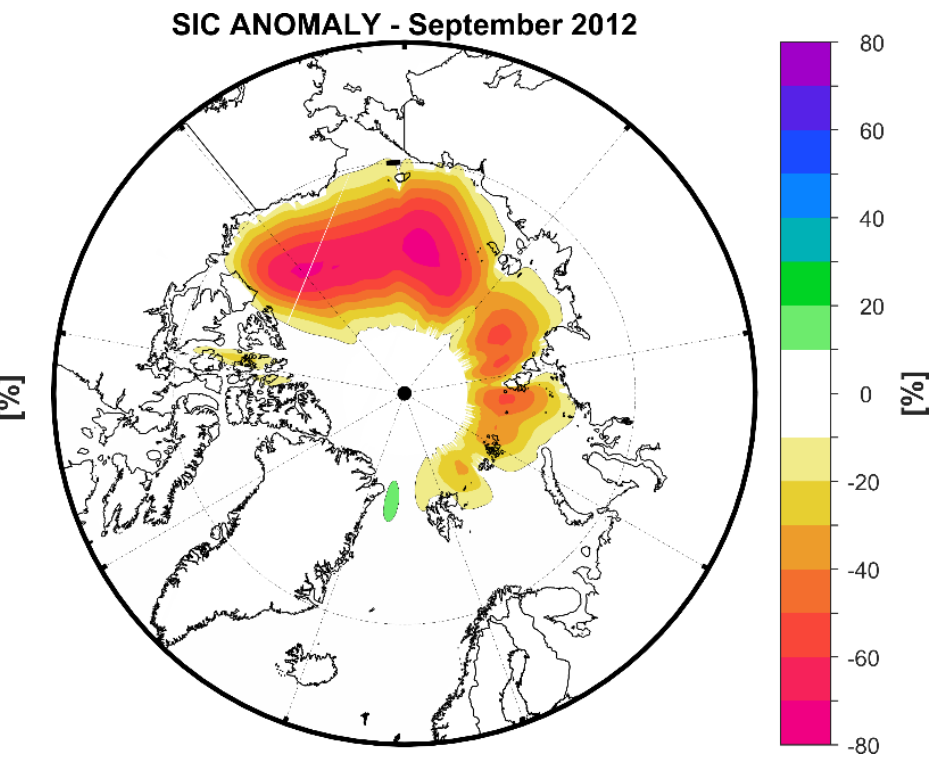

c)

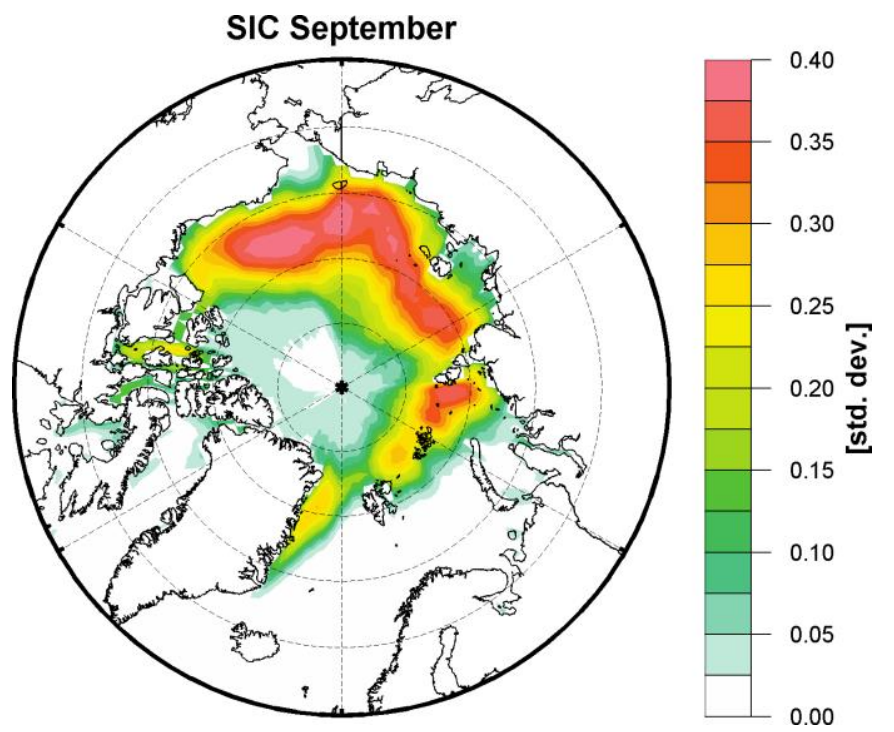

Figure S1. a) September sea ice concentration anomalies for 2007 against long-term mean 1981 - 2010; b) as in a) but for 2012 and c) the standard deviation of the September sea ice concentration. 
a)

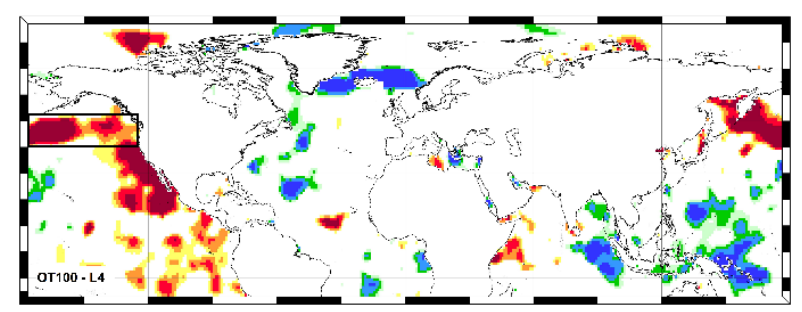

c)

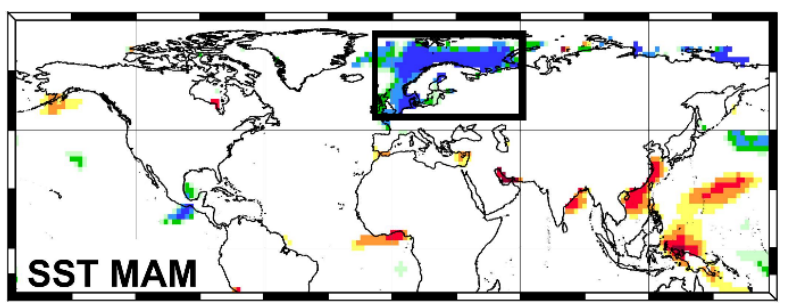

e)

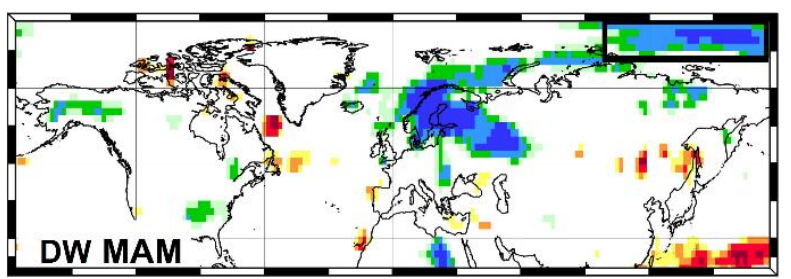

g)

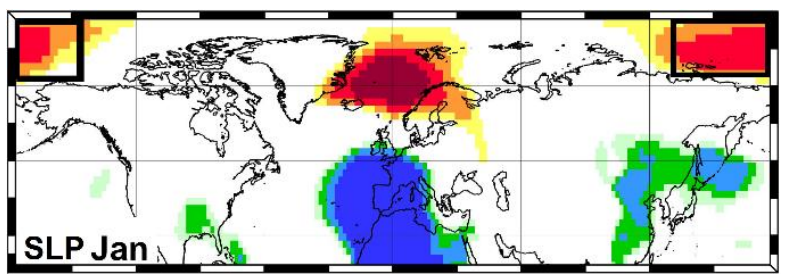

b)

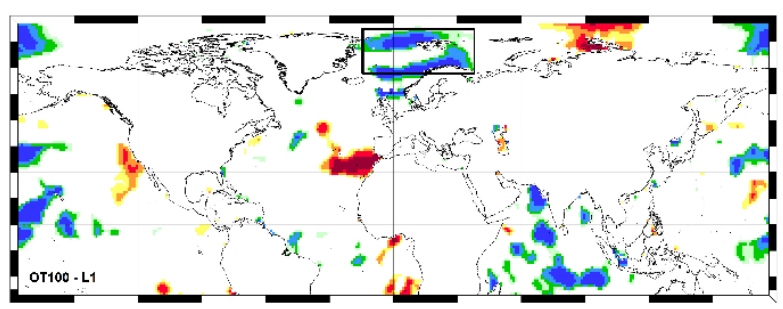

d)

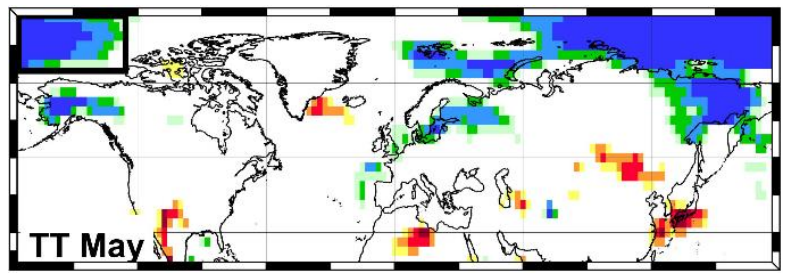

f)

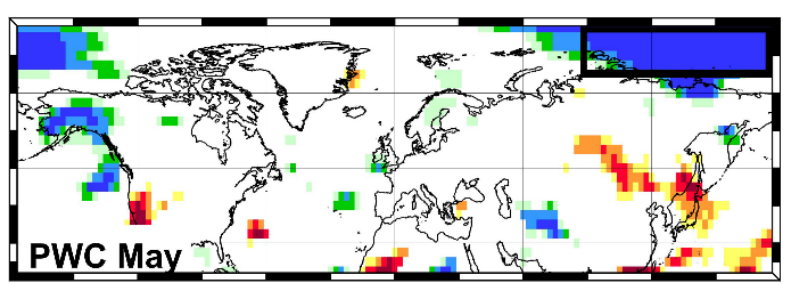

h)

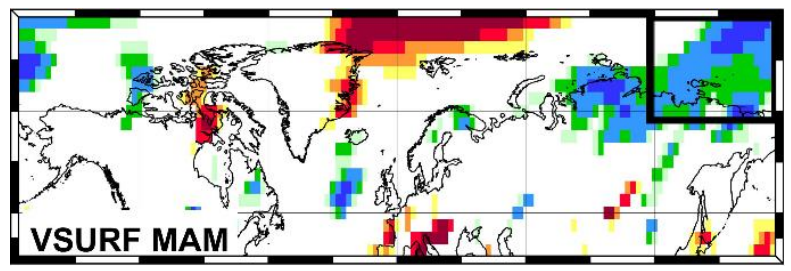

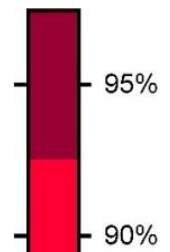

$85 \%$

$80 \%$

$-80 \%$

$-90 \%$

$-95 \%$

Figure S2. Stability map of the correlation between East Siberian September Sea Ice Extent and a) OT100 Annual (L4), b) OT100 Annual (L1), c) SST MAM, d) TT May, e) DW MAM, f) PWC May, g) SLP Jan and h) VSURF MAM. Regions where the correlation is stable, positive and significant for at least $80 \%$ windows are shaded with dark red (95\%), red (90\%), orange $(85 \%)$ and yellow $(80 \%)$. The corresponding regions where the correlation is stable, but negative, are shaded with dark blue $(95 \%)$, blue $(90 \%)$, green $(85 \%)$ and light green $(80 \%)$. 


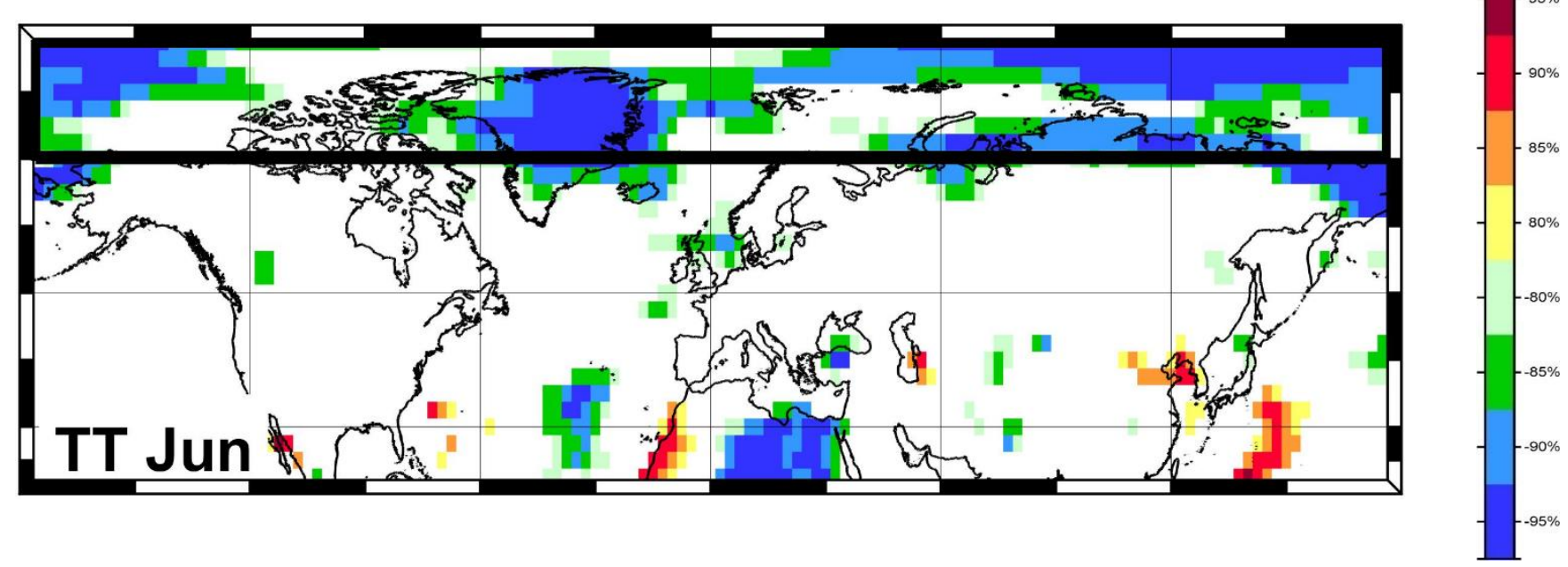

Figure S3. Stability map of the correlation between East Siberian SSIE and TT Jun. Regions where the correlation is stable, positive and significant for at least $80 \%$ windows are shaded with dark red $(95 \%)$, red $(90 \%)$, orange $(85 \%)$ and yellow (80\%). The corresponding regions where the correlation is stable, but negative, are shaded with dark blue (95\%), blue (90\%), green $(85 \%)$ and light green $(80 \%)$. 
a)

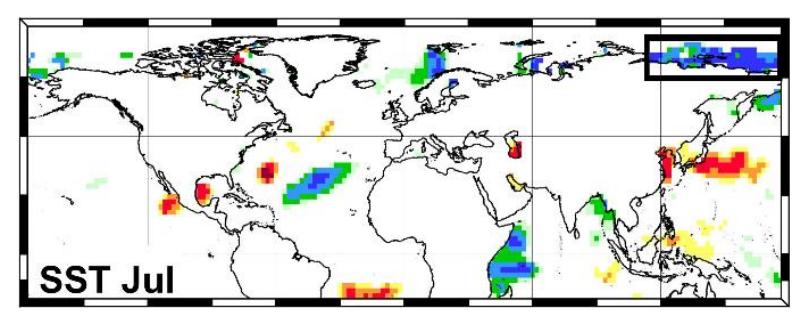

c)

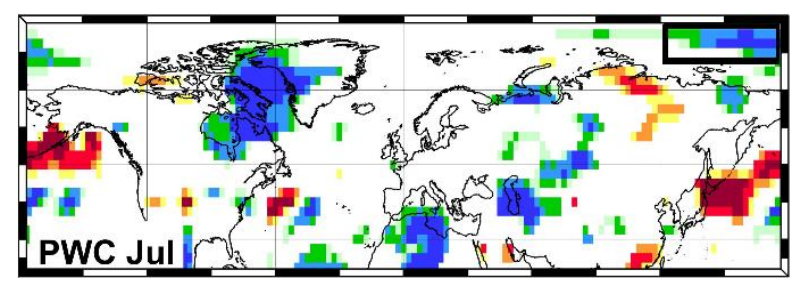

b)

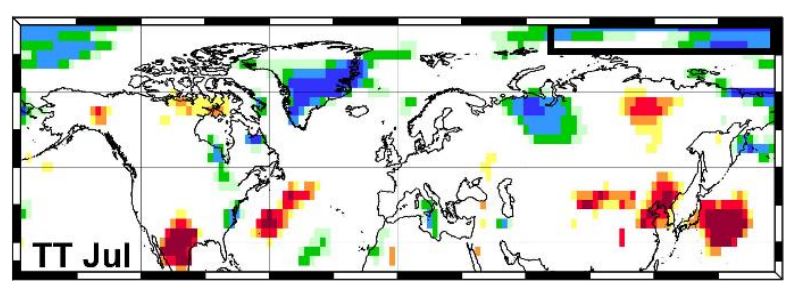

d)

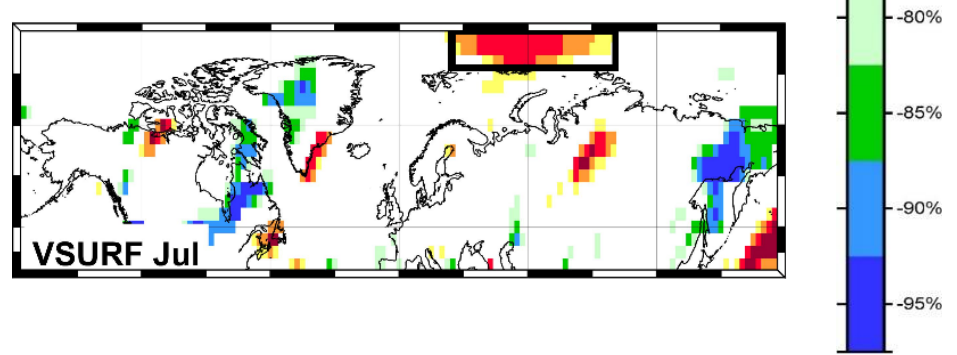

Figure S4. Stability map of the correlation between East Siberian SSIE and a) SST Jul, b) TT Jul, c) PWC Jul and d) VSURF Jul. Regions where the correlation is stable, positive and significant for at least $80 \%$ windows are shaded with dark red $(95 \%)$, red (90\%), orange (85\%) and yellow (80\%). The corresponding regions where the correlation is stable, but negative, are shaded with dark blue (95\%), blue (90\%), green (85\%) and light green $(80 \%)$. 
Table S1. Skill parameters (see supplementary file for definition) based on different statistical methods for the observed and predicted pan-Arctic sea ice extent in September with different time lags.

\begin{tabular}{|l|r|r|r|r|r|r|}
\hline & \multicolumn{2}{|c|}{ May } & \multicolumn{2}{c|}{ June } & \multicolumn{2}{c|}{ July } \\
\hline & Calibration & \multicolumn{1}{|c|}{ Validation } & Calibration & Validation & Calibration & Validation \\
\hline MAE & 0.18 & 0.23 & 0.16 & 0.19 & 0.15 & 0.17 \\
\hline MSE & 0.05 & 0.08 & 0.04 & 0.06 & 0.04 & 0.05 \\
\hline RMSE & 0.22 & 0.29 & 0.2 & 0.24 & 0.19 & 0.23 \\
\hline NRMSE \% & 41.7 & 53.4 & 38 & 44.4 & 37.3 & 43 \\
\hline NSE & 0.82 & 0.68 & 0.85 & 0.78 & 0.86 & 0.8 \\
\hline mNSE & 0.54 & 0.42 & 0.6 & 0.53 & 0.62 & 0.58 \\
\hline rNSE & 0.94 & 0.42 & 0.96 & 0.68 & 0.96 & 0.75 \\
\hline d & 0.95 & 0.88 & 0.96 & 0.93 & 0.96 & 0.94 \\
\hline md & 0.76 & 0.66 & 0.79 & 0.74 & 0.81 & 0.78 \\
\hline rd & 0.98 & 0.78 & 0.99 & 0.9 & 0.99 & 0.92 \\
\hline cp & 0.91 & 0.85 & 0.94 & 0.89 & 0.94 & 0.89 \\
\hline r & 0.90 & 0.84 & 0.92 & 0.89 & 0.93 & 0.90 \\
\hline R & 0.81 & 0.71 & 0.85 & 0.79 & 0.86 & 0.81 \\
\hline
\end{tabular}


Table S2. Skill parameters (see supplementary file for definition) based on different statistical methods for the observed and predicted East Siberian sea ice extent in September with different time lags.

\begin{tabular}{|c|c|c|c|c|c|c|}
\hline & \multicolumn{2}{|c|}{ May } & \multicolumn{2}{|c|}{ June } & \multicolumn{2}{|c|}{ July } \\
\hline & Calibration & Validation & Calibration & Validation & Calibration & Validation \\
\hline MAE & 0.07 & 0.09 & 0.05 & 0.08 & 0.04 & 0.07 \\
\hline MSE & 0.01 & 0.01 & 0 & 0.01 & 0 & 0.01 \\
\hline RMSE & 0.08 & 0.12 & 0.07 & 0.1 & 0.06 & 0.09 \\
\hline NRMSE \% & 34.4 & 61.9 & 29.8 & 52.7 & 25 & 44.4 \\
\hline NSE & 0.88 & 0.57 & 0.91 & 0.69 & 0.94 & 0.78 \\
\hline mNSE & 0.61 & 0.33 & 0.69 & 0.43 & 0.75 & 0.44 \\
\hline rNSE & 1 & 0.83 & 1 & 0.87 & 1 & 0.9 \\
\hline $\bar{d}$ & 0.97 & 0.86 & 0.98 & 0.91 & 0.98 & 0.93 \\
\hline md & 0.81 & 0.65 & 0.84 & 0.71 & 0.87 & 0.71 \\
\hline rd & 1 & 0.94 & 1 & 0.96 & 1 & 0.97 \\
\hline cp & 0.88 & 0.81 & 0.91 & 0.86 & 0.94 & 0.9 \\
\hline $\mathbf{r}$ & 0.94 & 0.77 & 0.95 & 0.84 & 0.97 & 0.90 \\
\hline $\mathbf{R}^{2}$ & 0.88 & 0.58 & 0.91 & 0.71 & 0.94 & 0.81 \\
\hline
\end{tabular}

